\title{
DISGUSSION
}

S. C. Colbeck: It is encouraging to see that you understand the physics of the problem. Do you have any suggestions for practical solutions to the problem at this time?

S. F. AcKLEy: This is obviously a leading question by a well-known provocateur at these meetings. We are continuing with our investigations. We are particularly interested at this time in the shedding problem.

R. List: The applied heat-transfer equation is for slowly rotating cylinders with quasisymmetric accretion and transfer. The situation for helicopter blades is quite different. Further, J. N. Carras and W. C. Macklin's data on shedding are for situations without the high angular accelerations observed for blades. Higher angular accelerations will enhance shedding considerably. The distinction between wet and dry growth is quite academic because even at surface temperatures below $0^{\circ} \mathrm{C}$ parts of the surface will be liquid at any one time. I agree with the author that the heat transfer (through conduction) from the part of the blade without deposit to the part covered by ice could be crucial. In general, however, I feel that the phenomenon of helicopter blade icing is better described by empirical equations than by modelling on the basis of an unsatisfactory theory.

AcKLEY: In reference to the use of the shedding data from lower velocities, I should point out that we have not used the quantitative values but only the implied dependence as given by Carras and Macklin, I feel there is a need for more experimentation but am encouraged by the qualitative similarity between the "extended prediction" using Carras and Macklin's results and the observed ice thickness from our experiments. There may not be the strong angular acceleration dependence for shedding that $\mathrm{Dr}$ List has stated but not proven. A similar reply may also apply for the use of the heat-transfer equation, i.e. there is reasonable agreement, here more quantitative, with the prediction of the heat-transfer equation and the transition from dry to wet growth. Therefore the heat-transfer equation we use may be more valid than Dr List would care to admit.

The wet and dry growth transition is not academic because it seems uniquely to define whether water is shed or not. I would concur that there is probably a temperature rise to $0^{\circ} \mathrm{C}$ as a droplet impinges, however, if the heat transfer is adequate we may assume that it is completely frozen without shedding. This leads to a linear dependence of ice thickness with velocity in the dry-growth regime and a non-linear dependence on velocity in the wet-growth regime. The transition also appears to be well defined by ice structure and is fairly predictable from the assumptions in the heat transfer causing a surface temperature of $0^{\circ} \mathrm{C}$.

The dialectic between modelling and experiments is the guts of any scientific advance and is crucial to the understanding of the process so I am in complete disagreement with Dr List in his emphasis on empiricism rather than theory.

\section{A STUDY OF SEVERAL PRESSURE RIDGES AND ICE ISLANDS IN THE CANADIAN BEAUFORT SEA}

\author{
By J. Hnatiuk, \\ (Gulf Oil Canada Ltd., P.O. Box 130 , Calgary, Alberta $\mathrm{T}_{2} \mathrm{P}_{2} \mathrm{H}_{7}$, Canada)
}

\section{A. Kovacs and M. Mellor \\ (U.S. Army Cold Regions Research and Engineering Laboratory, Hanover, New Hampshire 03755, U.S.A.)}

Abstract. The environment conditions in the southern Beaufort Sea are described with special emphasis on pressure ridges and ice islands. Techniques for determining the geometric 
configurations and the physical and mechanical properties of sea-ice structures and ice islands are described. Profiles of pressure ridges were determined by surface surveys, drill-hole probes and side-looking sonar scanning. Multi-year pressure ridges with thicknesses up to $\mathrm{I} 8 \mathrm{~m}$ and widths up to I I $\mathrm{m}$ were examined in detail. The first-year ridge of $22 \mathrm{~m}$ thickness and $100 \mathrm{~m}$ width was studied. Results are given for several multi-year ridges and the first-year ridge. Information obtained from dives under the ice is also given. Corresponding data are given for grounded ice islands with particular attention being given to contact between the ice and sea bed. A $19 \mathrm{~m}$ thick ice-island fragment grounded in $13 \mathrm{~m}$ of water was one of several investigated. Measurements of temperature, salinity, tensile strength and compressive strength are given for ice taken from old pressure ridges and factors influencing the interpretation of test data are discussed. The data obtained in this study will be used in engineering design studies for off-shore structures for drilling and production of hydrocarbons from the Beaufort Sea area. Exploratory drilling in shallow water has already been carried out and off-shore drilling from drill ships is scheduled to commence in the study area during the open-water season of 1976 .

This paper will be published in full in a future issue of Journal of Glaciology.

\section{DISGUSSION}

E. Kopaygorodskiy: Have you studied the mechanical properties of the sail and the keel?

J. HNAtiuk: We realize that the mechanical properties of pressure-ridge ice are important and performed some Brazil, compressive and tensile strength tests. The results were rather lower than expected, probably because of difficulties with specimen preparation. One can also infer the ice strength from a knowledge of its brine concentration and temperature.

KopAYgorodskiy: How does the load imposed on a structure by a pressure ridge compare with that due to a smooth sheet of ice?

HnAтıu: The loads imposed will certainly be higher than for sheet ice, but have not been measured by us. Some measurements on thinner ridges have been made by Imperial Oil.

W. F. WEEKS: Most parts of multi-year ridge ice behave like cold, low-salinity ice. We might consider sea ice to be a composite of this ridge ice and thinner sheet ice in evaluating its mechanical properties and the loading effect on structures.

KOPAYGORODSKIY : Were any attempts made to develop a laboratory model of pressure ridges? HNATIUK: We have certainly considered a model, but this has not yet been done.

D. BRUCE: Could you comment on the soil characteristics at the location of the deep ice scour?

Hnatiuk: In the Mackenzie Delta this is clay or silty clay. Further north the soil is more sandy.

H. FAngel: Can any indication be given of the age of grounded ice islands in the Beaufort Sea?

HNatiuk: The fact that the thickness has decreased from about $55 \mathrm{~m}$ on calving at Ellesmere Island to about $25 \mathrm{~m}$ on grounding may give some clue. A substantial calving in the mid $60 \mathrm{~s}$ resulted in several fragments being grounded on the Alaska coast in 1972. Perhaps our fragments are of a similar age.

S. F. Ackley: Were your island fragments observed to remain throughout the summer, or were they carried away during the ice-free period?

HNatiuk: Our fragments all moved out the next season, though some stayed till close to the end of the summer. 